Money for space science

\section{Tokyo}

Astronomy and space science have done particularly well in the 1991 budget for Japan's Ministry of Education, Science and Culture (MESC) which was released last week. Funds have been allocated to begin building one of the world's largest optical infrared telescopes in Hawaii and to develop a scientific satellite that will be sent to the Moon. Astrophysicists have also won some money to excavate a giant underground hole to accommodate the world's largest observatory for neutrinos and proton decay - provided that a budget for the observatory is allocated at some future date.

The highlight of the budget, which has to be approved by the Diet before it takes effect at the beginning of April but is unlikely to undergo change, is an allocation of $¥ 663$ million ( $\$ 4.9$ million) to begin construction of an 8-metre infrared optical telescope in Mauna Kea in Hawaii. Researchers at the National Astronomical Observatory, which until recently was part of Tokyo University, have been pushing for the telescope for years but have been hampered by MESC's limited budget and by bureaucratic regulations that make it difficult to establish facilities overseas (see Nature 311, 5; 1984).

Most of this year's allocation will go towards building the giant mirror for the telescope, says Makoto Kinoshita of

\begin{tabular}{lrc}
\hline \multicolumn{3}{c}{ MESC BUDGET } \\
\hline & \multicolumn{2}{c}{$\begin{array}{c}\text { percentage } \\
\text { Thousand }\end{array}$} \\
& $\begin{array}{c}\text { change } \\
\text { million }\end{array}$ & from 1991 \\
Grants-in-aid of research & 58.9 & +5.5 \\
Government/industry research & 13.4 & +16.5 \\
Donations from industry & 44.3 & +13.0 \\
Nuclear fusion & 8.8 & -1.8 \\
Accelerator physics (TRISTAN) & 15.8 & -2.7 \\
Space science & 20.8 & +15.6 \\
Astronomy & 1.7 & +95.2 \\
Earth science & 2.3 & +1.1 \\
Antarctic research & 3.1 & -40.2 \\
Domestic research fellowships & 2.4 & +8.5 \\
\hline
\end{tabular}

MESC's research institute division. Several foreign companies are keen to get the job. A contractor will be selected after passage of the budget by the Diet, Kinoshita says.

Construction of the complete facility is expected to take eight years at a total cost of about $¥ 38,000$ million ( $\$ 281$ million).

Competing for funds is a proposal to build a giant observatory for neutrinos and proton decay in a mine in Gifu Prefecture. Researchers at Tokyo University's Institute for Cosmic Ray Research had hoped to get a budget for the observatory, called Superkamiokande, this year but instead will have to make do with funds to excavate a hole 40 metres wide by 40 metres deep for the facility. But MESC officials say that although Superkamiokande, which is expected to cost about $¥ 8,700$ million (\$64 million), has yet to win full approval, it is most unlikely that anybody would dig such a big hole and not put anything in it.

Another project to win support is an ambitious plan from the Institute of Space and Astronautical Science (ISAS) to send a satellite to the Moon that will drop penetrators into the lunar surface to measure 'moonquakes'. The mission is a follow-up to ISAS's successful launch of a lunar probe last year (Nature 344, 693; 1990 ). An allocation of $¥ 380$ million (\$2.8 million) has been made for the new lunar project in 1991. Apart from this project, the main reason for the large increase in MESC's allocation for space science is increased outlays for development of the $\mathrm{M}-\mathrm{V}$ rocket that will carry the lunar spacecraft aloft and for a VLBI radiotelescope satellite that will be launched before the lunar mission.

MESC's science budget is subject to strict limitations laid down by the Minsitry

of Finance and cuts have had to be made elsewhere to make way for the increased outlays for space science and astronomy. Among the projects to suffer is TRISTAN, the huge electron-positron collider at the High Energy Physics Laboratory in Tsukuba. Operating hours for the collider have been reduced by 100 hours to 2,800 hours in 1991. But MESC officials say they are still committed to the accelerator (there have been suggestions that TRISTAN's main ring should be converted into a $10-\mathrm{GeV}$ synchrotron). Among the new items in MESC's budget is reference to a "new" and "large-scale" human genome project. But MESC officials say that the precise budget for the project has yet to be decided. Last year it was announced that the ministry hopes to increase grants for genome research from $¥ 280$ million to about $¥ 500$ million (\$3.7 million) per year in 1991. And MESC is also seeking $¥ 850$ million over five years to establish a new Genome Analysis Centre at Tokyo University's Institute of Medical Science.

David Swinbanks

\title{
TNF production licensed
}

\section{Munich}

IN an encouraging development for the German pharmaceutical industry, the city of Ludwigshafen in southwest Germany last week approved the production of recombinant tumour necrosis factor (TNF) by the chemical and pharmaceutical company BASF AG.

This is only the fourth licence for the production of a recombinant medicine to have been issued in Germany. The others went to Boehringer Ingelheim for tissue plasminogen activator (TPA), Grünenthal AG for the anti-clotting drug Saruplase and Behringwerke AG for erythropoietin (EPO).

The approval was particularly encouraging for the biotechnology industry because it means that another region of Germany has decided that it can live with the risks of pharmaceutical production using genetic engineering. The situation is likely to improve, because future licence applications will be regulated under last year's federal law, which allows companies to win a licence without public participation if they use safety strains of bacteria.

BASF hopes to produce 500 grams of TNF a year for use against tumour-related ascitis (also known as abdominal dropsy), a condition of some abdominal cancers in which the abdominal cavity may accumulate as much as 10 litres of fluid. Hitherto, this condition has been relieved by withdrawing the fluid mechanically, but it quickly returned. Three treatments with TNF alleviate the condition, says a
BASF spokeswoman, although the tumours remain.

Despite early setbacks in the use of TNF to reduce tumours - it seemed to shrink all else but the tumours in early US trials - BASF remains hopeful that TNF will be useful in the treatment of cancer. In combination with $\alpha$-interferon, TNF has been shown in clinical trials to help to shrink tumours and reduce metastases in 40 per cent of renal cell carcinoma patients.

The decision to grant BASF a licence may help to stem the exodus of pharmaceutically inspired genetic engineering research from Germany. In 1988, BASF decided to move most of its research in the field to the United States, which seemed to offer a friendlier climate than Germany.

There also seems to have been a regulatory impulse behind the application for a licence. BASF had produced the TNF used in German clinical trials at its home base of Ludwigshafen - the US Food and Drug Administration requires that a drug approved for clinical use must be produced in the same plant as that used for making the samples used in clinical trials.

BASF also applied last month to the Federal Health Office (BGA) in Berlin for permission to market TNF in Germany. If BGA finds the application in order, it will pass it on to Brussels, which can approve TNF for use in all 12 member states of the European Communities.

Steven Dickman 